\title{
Fusidic Acid
}

National Cancer Institute

\section{Source}

National Cancer Institute. Fusidic Acid. NCI Thesaurus. Code C65793.

A bacteriostatic antibiotic derived from the fungus Fusidium coccineum and used as a topical medication to treat skin infections. Fusidic acid acts as a bacterial protein synthesis inhibitor by preventing the turnover of elong ation factor $\mathrm{G}$ (EF-G) from the ribosome. Fusidic acid is effective primarily on gram-positive bacteria. 